УДК 159.9.072

DOI: $10.18384 / 2310-7235-2015-4-27-37$

\author{
Цветкова Н.А.', Рыбакова А.И., Старцева Н.Г. \\ ${ }^{1}$ Российский государственный социальный университет (г. Москва) \\ ${ }^{2}$ Центра реабилитации инвалидов и инвалидов детства (г. Санкт-Петербург)

\section{ПСИХОЛОГИЧЕСКАЯ ПОМОЩЬ ЛИЧНОСТИ, ПЕРЕЖИВАЮЩЕЙ КРИЗИС СТАРОСТИ}

Аннотация. В статье поднимается проблема оказания психологической помощи людям в период кризиса столкновения со старостью. Усиление социальной потребности в психологической помощи пожилым людям объясняется, с одной стороны, особенностями личностного и социального развития человека в данном возрастном периоде, а с другой феноменом старения населения; раскрывается содержание понятия «кризис старости», ставится проблема определения временных рамок старости как возрастного периода жизни человека; приведены результаты эмпирического исследования особенностей личности в возрасте кризиса перехода к старости; дана социально-психологическая характеристика мужчин и женщин, переживающих кризис старости, и представлена авторская программа оказания им психологической помощи; приведены результаты апробации программы.

Ключевые слова: личность в возрасте перехода к старости, кризис старости, психологическая помощь, биографический и нарративный подходы, метод рассказывания историй, метод написания автобиографии; программа психологической помощи клиентам, переживающим кризис старости.

\author{
N. Tsvetkova' ${ }^{1}$, A. Rybakova ${ }^{1}$, N. Startseva ${ }^{2}$ \\ ${ }^{1}$ Russian State Social University, Moscow \\ ${ }^{2}$ Centre of Social Rehabilitation of Invalids and Children-Invalids, St. Petersburg
}

\title{
PSYCHOLOGICAL CARE OF A PERSON EXPERIENCING THE OLD AGE CRISIS
}

Abstract. The article raises the problem of providing psychological support to people facing the old age crisis. The growing need in psychological care for older people is explained, on the one hand, by the peculiarities of personal and social development characteristic for this age period, and, on the other hand, by the phenomenon of population ageing. The content of the concept "old age crisis" is interpreted. The problem of determining the time frame of the old age as the age of human life period is put forward. The author's program of providing them a psychological support is presented. The results of testing the program are given.

Key words: personality at the age of transition to old age, old age crisis, biographical and narrative approaches, story-telling method, method of biography-writing, program of psychological support to clients experiencing the old age crisis.

Феномен старения населения - проблема не только социально-демографическая, но и социально-психологическая. Превращение общества в «мир старых

(с Цветкова Н.А., Рыбакова А., Старцева Н.Г., 2015. 
людей» ставит перед современной психологией много вопросов, например, как протекает психологическое старение и какова его взаимосвязь с биологическим старением, каковы перспективы включения стареющего человека в разные сферы общественной жизни, каковы возможности сохранения (или достижения) психологического благополучия в старости, возможна ли самореализация человека в пожилом возрасте, каково влияние общественных стереотипов на характер старения и др.

Стоит отметить, что поздняя зрелость (пожилой возраст) в науке до сих пор рассматривается неоднозначно: от 50 до 75 лет (Биррен Д., 1964); от 40 до 55 лет, а с учетом переходной стадии - до 65 лет (Бромлей Д., 1966); от 65 лет (Эриксон Э., 1963); от 60 до 75 лет (Фельдштейн Д.И., 1999); от 65 лет (Реан А.А., 2007). По классификации Европейского регионального бюро ВО3, старение (пожилой возраст) длится у мужчин с 61 до 74 лет, у женщин - с 56 до 74 лет. С 75 лет наступает старость (преклонный возраст). Период старше 90 лет - долгожительство (старчество).

Научно доказано $[3 ; 4 ; 6 ; 7 ; 8 ; 9 ; 11$; $13 ; 18]$, что кризисы взрослости меньше, чем в детстве, зависят от хронологического возраста и в большей степени определяются личными обстоятельствами жизни человека; они могут подготавливаться постепенно или возникать внезапно в случае резкого изменения в социальной ситуации развития - системе отношений между личностью и окружающей ее социальной действительностью.

Кризис на границе зрелости и старости датируют примерно возрастом 56-65 лет. Его содержание в психоло- гии представлено нечетко, чаще всего его связывают с выходом на пенсию. Другая точка зрения на кризис перехода к старости состоит в том, что это, прежде всего, кризис идентичности. Физиологическое старение в силу его постепенности долгое время не осознается, возникает иллюзия «неизменности» самого себя. Осознание старения бывает неожиданным и мучительным, что приводит к различным внутриличностным конфликтам [18].

А.И. Анцыферова выделяет два типа развития личности в этот период: представители первого типа относительно легко переживают уход на пенсию, второго - погружаются в прошлое и, даже будучи физически здоровыми, быстро дряхлеют [1].

В 1984 г. И.С. Кон в книге «В поисках себя: личность и ее самосознание» привел классификацию благополучных типов старости в зависимости от направленности той деятельности, которой занят человек: I тип - активная, творческая старость (даже если человек прекратил заниматься профессиональным трудом, он продолжает участвовать в общественной деятельности, его жизнь насыщена и событийна, он ощущает чувство собственной полноценности); II тип - обустройство собственной жизни (представители этого типа старости отличаются хорошей социально-психологической адаптивностью, но их активность преимущественно направлена на обеспечение материального благополучия, отдых, развлечение и самообразование, на что раньше было мало времени); III тип - семейно ориентированный (в нем преобладают женщины, которым некогда хандрить и скучать, они много делают для близких и род- 
ных, тем не менее удовлетворенность жизнью у них ниже, чем у представителей первых двух типов старости); IV тип - люди со здоровьесберегающей ориентацией (смысл их жизни - забота о здоровье, ради этого они проявляют свою активность и в случае успеха получают моральное удовлетворение; склонны преувеличивать свою немощь и «страдать» от мнимых болезней).

Он также представил два неблагополучных типа старости - это: а) агрессивные ворчуны, всем недовольные, критикующие все, кроме себя; б) разочарованные в себе и собственной жизни, одинокие и печальные неудачники, обвиняющие себя за упущенные возможности - действительные и мнимые.

В зависимости от стратегий приспособления к жизни в позднем возрасте английский психолог Д.Б. Бромлей описала пять типов личностных черт старения: 1) конструктивный тип; 2) зависимый тип; 3) защитный тип; 4) агрессивно-обвинительный тип; 5) самообвинительный тип [6, с. 128].

Существует целый ряд других типологий (Е.С. Авербух, Ф. Гизе и др.) и их разработка продолжается, поскольку, как отмечает А.В. Толстых [15, с. 173], в старости картина измерений личности насыщена разнообразным набором качеств, которые редко встречаются в одном человеке. По этой причине существует необходимость создания различных типологий старости.

Даже краткое введение в проблему кризиса перехода к старости позволяет заметить, что в психологии накоплен определенный материал, раскрывающих социально-психологическую проблематику людей этого возрастного периода и дающий характеристику личности в возрасте от 56 лет и далее, однако общепринятых научных выводов пока нет. Тем не менее есть люди - конкретные мужчины и женщины, для которых этот возраст становится социально-психологической проблемой, причем в силу сложившейся демографической ситуации их число неуклонно растет.

Проведенное нами в 2013-2015 гг. в Санкт-Петербурге эмпирическое исследование позволило выявить ряд типичных особенностей личности в возрасте кризиса перехода к старости. В исследовании приняли участие 60 человек (20 мужчин и 40 женщин) в возрасте от 56 до 70 лет (средний возраст 61 год). Чуть более половины представителей этой выборки имели высшее образование (53,3\%); работали, будучи пенсионерами (73,3\%). Большая часть обследованных состояла в браке (60 \%) и имела взрослых детей $(83,3 \%)$, но проживала отдельно от них (86,6 \%). Психодиагностика осуществлялась по желанию, у пожилых людей не было запросов о психологической помощи. Однако в процессе диагностирования была выявлена основная проблема, беспокоившая практически каждого из них, - это состояние внутреннего дискомфорта (люди отмечали: раньше они были активны, у них были силы и желания, а сейчас этого нет).

Использовались следующие методики: 1) СМОЛ - вариант опросника MMPI; 2) методика диагностики социально-психологической адаптации К. Роджерса и Р. Даймонда (СПА); 3) индекс жизненной удовлетворенности (ИЖУ в адаптации Н.В. Паниной); 4) тест смысложизненных ориентаций Д.А. Леонтьева (СЖО); 5) опросник временной перспективы (Ф. Зимбардо, 1999) в адаптации А. Сырцо- 
вой, Е.Т. Соколовой, О.В. Митиной; 6) «Психологическая автобиография» (Л.Ф. Бурлачук, Е.Ю. Коржова, 1994).

Анализ данных, полученных с помощью указанных методик психодиагностики, позволил установить, что:

1. Из всей выборки кризис перехода к старости переживали 18 чел. (30\%). У них выявлено: нарушение временной перспективы (устремленность в прошлое или в будущее); пессимистическое отношение к прошлому, что связано с реальными неприятными и психотравмирующими событиями или негативной реконструкцией положительных событий; социальная дезадаптированность; пассивная, подчиненная роль в межличностных отношениях; низкая ориентированность на социальное окружение; отсутствие целей в жизни; неудовлетворенность своей прошлой и настоящей жизнью; неверие в свои силы контролировать события собственной жизни; фатализм, убежденность в бессмысленности попыток изменить что-либо; эмоциональная напряженность, повышенная тревожность, ощущение внутреннего дискомфорта.

2. Исследование не выявило значительных гендерных различий. Однако обследованным нами женщинам в большей степени, в отличие от мужчин, свойственны такие черты, как склонность к аффектам, обидчивость, упрямство, трудолюбие, изобретательность, искренность и наивность. У мужчин более выражено стремление к доминированию в межличностных отношениях. Эмоциональное состояние у женщин более пессимистичное, чем у мужчин.

3. Кластерный анализ данных позволил из общего количества обсле- дованных мужчин и женщин выделить 4 группы:

I группа - социально ориентированные мужчины и женщины (22 чел. - $37 \%)$. Это наиболее пожилые участники исследования (средний возраст - 62 года), с наибольшим количеством детей, преимущественно одинокие вследствие развода или вдовства. У них самые низкие показатели по шкалам психопатии, паранойяльности и гипомании; самая высокая ориентированность на социальное окружение, причем они стремятся представить себя в выгодном свете; самый низкий показатель «гедонистическое настоящее» и на нижней границе нормы - показатель «позитивное прошлое»;

II группа - мужчины и женщины с личностными деформациями, переживающие кризис старения (18 чел. $30 \%)$. В большинстве своем они имеют среднее специальное образование, продолжают работать; у них самые высокие показатели по шкалам ипохондрии, депрессии, паранойяльности, истерии, психастении, шизоидности; высокие показатели негативного прошлого, фаталистического настоящего; самые низкие показатели по адаптивности (дезадаптированность), принятию других и особенно по доминированию; низкой является и ориентированность на социальное окружение. Ниже других групп у данной группы показатели шкал: цели, процесса и результативности жизни, ее осмысленности и локуса контроля, а также общий фон настроения и индекс удовлетворенности жизнью, согласованность между поставленными целями и их достижением, последовательность в достижении целей и интерес к жизни; 
III группа - хорошо адаптированные люди, успешно преодолевающие кризис столкновения со старостью (16 чел. - 26 \%). Большинство обследованных этой группы - малодетные мужчины с высоким уровнем образования, проживающие отдельно от детей;

IV группа - женщины, чьи результаты представляют собой отдельные частные случаи (4 чел. - $7 \%$ ). Средний в проживает совместно с детьми. Наивысшие показатели отмечены по шкалам лживости, принятия других, эскапизму; гипомании и психопатии. Высокими являются согласованность между поставленными и достигнутыми целями, а также последовательность в их достижении, показатель «гедонистическое настоящее»; самыми низкими - показатели самопринятия, эмоционального комфорта, интернальности, шизоидности. Низкий локус контроля-Я, низкий уровень желания подать себя в выгодном свете; низкая самооценка; негативное восприятие прошлого.

4. Корреляционный анализ данных по Пирсону позволил выявить две закономерности: 1) чем выше уровень образования пожилого человека, тем выше его адаптивность, осмысленность жизни, целеустремленность, самореализация; 2) чем выше уровень образования, тем ниже уровень эскапизма, а восприятие прошлого и настоящего более оптимистично.

Анализ отечественной и зарубежной научно-практической литературы [2; 5; 9; 10; 14] показывает, что с целью оказания психологической помощи пожилым людям чаще всего применяются аналитически ориентированные беседы, личностно ориентированное консультирование и групповые за- нятия. Опыт работы психологов с пожилыми людьми [5; 9] свидетельствует о применении технологий и методов всех основных направлений психологического консультирования возрастно-психологического, индивидуального, группового (в том числе семейного), профориентационного, психологического консультирования по специальным проблемам. Для достижения целей индивидуального социально-психологического консультирования пожилых людей часто используются биографический и нарративный подходы.

Биографический подход в оказании психологической помощи пожилым людям основывается на исследовании жизненного пути человека. Основными источниками биографических данных являются официальные биографические документы (свидетельство о рождении, паспортные данные, дипломы, характеристики, автобиографии и др.), результаты практической деятельности (статьи, книги, картины, авторские свидетельства и др.), а также фотографии, документальные фильмы и др. Их использование с целью восстановления хронологической последовательности жизненных событий дает человеку в возрасте столкновения со старостью возможность осознать, как его прошлое определяет его настоящее и обусловливает будущее, признать ценность прошлого, научиться использовать полученный опыт и стратегии, которые ранее помогали справляться с трудностями, изменить стиль жизни. Кроме того, биографические факты дают психологу основания для планирования психокоррекционного вмешательства, если под угрозой оказывается достоинство личности и идентичность 
пожилого клиента. Для этого применяеются методы - рассказа историй и написания личной биографии. Метод рассказа историй служит средством «наведения мостов» между психологом и пожилым клиентом, позволяет преодолеть возрастные различия, создать атмосферу доверия во взаимоотношениях. Рассказываемые истории подтверждают личностную и социальную идентичность стареющего человека, помогают ему научиться управлять текущей ситуацией. Метод написания личной биограбии позволяет пожилому человеку адекватно оценить свое положение в наличной ситуаци, увидеть альтернативы его изменения и разрешить текущие проблемы.

Нарративный подход («повествовательный» от англ. narrative - история, повествование) более эффективен в тех случаях, когда в процессе индивидуальной работы с человеком пожилого возраста выявляется проблема, оказывающая сильное негативное влияние на его жизнь. Термин заимствован из историографии, где он использовался при разработке концепции «нарративной истории», рассматривающей исторические события как возникшие не в результате закономерных исторических процессов, а в контексте рассказа об этих событиях и неразрывно связанные с их интерпретацией. Нарративный подход в психотерапии появился в 80-х гг. XX века, когда австралиец М. Уайт и новозеландец Д. Эпстон опубликовали книгу «Narrative means to therapeutic ends», в России развивается с 2000 г. Основной метод работы в нарративном подходе - экстернализируюшая беседа, ключевой прием - дистанцирование клиента от проблемы (переживания). Основной частью рассказа и моментом появления в нем фабулы является его завершение. Рассказчик (нарратор) в первую очередь является носителем знания о финале, и только благодаря этому качеству он принципиально отличается от другого субъекта нарративного рассказа - его «героя», который, существуя в центре событий, не имеет этого знания. В ходе работы клиенты освобождаются от отнимающих силы чувств - стыда, вины и отвращения к себе, поэтому могут взять больше ответственности за свои поступки; проясняются смыслы, ценности, намерения, мечты, умения и возможности клиентов, прослеживается история их возникновения и развития. В итоге у человека формируется «безопасная территория идентичности», он может взглянуть на свою жизнь с ресурсной позиции и совершать осознанный выбор, меняя свою жизнь в желаемую сторону $[10 ; 16 ; 17]$.

Что касается оказания психологической помощи пожилым людям в условиях групповой работы, то здесь важно отметить, что зарубежные психотерапевты [17] рекомендуют с осторожностью применять психотерапевтические методы, поскольку основной механизм этой системы методов (эффективная обратная связь, позволяющая увидеть собственное неадекватные отношения и установки) в поздних возрастах может провоцировать повышение уровня тревожности, погружение в депрессию.

Эти результаты теоретического анализа проблемы оказания психологической помощи пожилым людям и данные собственного эмпирического исследования легли в основу разработанной и апробированной нами 
гендерочувствительной нарративнобиографической модели психологической помощи личности, переживающей кризис старости (напомним, что в нашей выборке таковых оказалось 18 чел., т.е. 30 \% обследованных - это мужчины и женщины с личностными деформациями (см. выше характеристику II кластера).

В качестве принципов оказания психологической помощи человеку, переживающему кризис старости, в нашей модели выступили:

- принцип геронтопсихологической компетентности, т.е. знание психологии пожилых людей, в том числе особенностей их психосексуального развития (задача психолога - информировать клиентов о возрастных особенностях и об их влиянии на жизнь пожилого человека, тем самым помочь понять, что с ним происходят естественные перемены, не являющиеся отклонением от нормы);

- принцип уникальности социально-психологической архитектоники личности, т.е. учет индивидуальных поло-возрастных особенностей конкретного человека (пожилого клиента) и их своеобразного сочетания к периоду столкновения с кризисом старости;

- принцип творения целостности сюжета судьбы пожилого клиента (принцип основан на концепции психологии судьбы, которая убеждает в том, что человек жаждет иметь такую (или так видеть) свою жизнь, чтобы о ней было интересно рассказывать). Человек хочет разнообразить прозу своей жизни, поэтому одно и то же событие он каждый раз может излагать по-иному. Это не заблуждение и не обман - так личность «сочиняет себя» в течение всей своей жизни, ассимили- руя происходящие с ней события, создавая события искусственные, часто бросая один сюжет и переходя к другому. «Счастлив тот, кто к концу своей жизни создал целостный сюжет своей судьбы», - утверждает В.М. Розин [12, c. 98]. Поэтому задача психолога - помочь клиенту, переживающему кризис старости, придать целостность процессу своей жизни, став для него терпеливым слушателем;

- учет сферы переработки конфликта, которую предпочитает пожилой клиент. Согласно одному из базовых положений позитивной психологии и психотерапии - теории конфликта, люди при столкновении с трудностями начинают интенсивно реализовывать одну из четырех возможностей их преодоления: 1) тело (известно, что переработка конфликта преимущественно посредством тела приводит к психосоматическим заболеваниям; психосоматические симптомы в период столкновения со старостью весьма характерны для некогда физически «очень красивых» женщин, которым, чтобы ослабить болезненные ощущения, предстоит понять, что их тело с каждым годом все меньше является фактором успеха во взаимоотношениях с другим полом, но ум и компетентность необычайно сексуальны в любом возрасте); 2) деятельность (профессиональная, хозяйственно-бытовая, досуговая); 3) общение (в семье и вне семьи); 4) уединение. В идеале нужно научиться использовать все эти возможности;

- принцип учета особенностей клиентов, проявляющихся в процессе индивидуальной беседы, а именно: 1) пожилой человек стремится руководить процессом консультирования (он «диктует», место, время периодич- 
ность и тематику очередной встречи, контролирует временные и содержательные рамки беседы). Если психолог сам четко регламентирует регулярность, длительность и периодичность встреч, то пожилой челове с большой долей вероятности воспримет это как принуждение и насторожится, замкнется или откажется от встреч; 2) пожилой клиент заранее готов обсуждать только один важный для него вопрос и, даже отвлекшись на другую проблематику, все равно возвращается к актуальной для него теме (из этого следует, что психологу необходимо поинтересоваться тем, что больше всего беспокоит пожилого клиента, о чем он сейчас думает); 3) рассказ клиента пожилого возраста следует выслушивать до конца, не перебивая, поскольку люди в этом возрасте трудно переключаются с одной темы на другую. В случае прерывания монолога клинты обычно переживают неприятные чувства - малоценность себя как личности и незначимость истории своей жизни, поскольку в силу возрастных особенностей они ищут не столько собеседника для диалога, сколько терпеливого слушателя, так как часто лишены этого в своей реальной жизни; 4) временные рамки консультативной беседы с пожилыми людьми подвижные и чаще широкие, причем продолжительность встречи всякий раз зависит от разных факторов (состояния здоровья клиента, его настроения, планируемой занятости в течение дня, особенностей контакта с психологом «здесь и теперь» и др.); 5) пожилые клиенты, получив возможность выговориться, на какое-то время прекращают подробные разговоры о своей жизни, однако их потребность в терпеливом слуша- теле лишь ослабевает, но никогда не удовлетворяется полностью;

- принцип поощрения позитивной самоподачи и обучения самоодобрению (так подкрепляется позитивная самоидентичность пожилого человека - «Я хороший человек»).

Разрабатывая программу психологической помощи личности, переживающей кризис старости, мы соединили некоторые возможности (теорию и методы работы) биографического и нарративного подходов и сделали акцент на принципе «творения целостности сюжета судьбы пожилого клиента», что, как мы предполагали, будет способствовать позитивному выходу клиентов из возрастного кризиса, а именно: изменению временной перспективы, преодолению социальной дезадаптации, прояснению жизненных целей, переоценке прошлой и оптимизации нынешней жизни, обретению способности контролировать события своей жизни, снижению эмоциональной напряженности и повышенной тревожности, обретению ощущения внутреннего равновесия и душевного комфорта.

Программа предполагала индивидуальную работу с клиентами и включала:

1) знакомство, заключение договора об оказании услуги, обсуждение методов работы над автобиографией, вхождение в роли: клиент-«рассказчик» консультант-«биограф», обсуждение вопроса о домашней работе и количестве встреч;

2) цикл встреч:

- встречи на тему «История моего тела»;

- встречи на тему «Моя профессионально-трудования деятельность»; 
- встречи на тему «Мои отношения и чувства»;

- встречи на тему «Мой досуг»;

- встречи на тему «Мой жизненный путь во времени и пространстве»;

- заключительная встреча и последнее редактирование биографии.

В конце каждой встречи давалось домашнее задание - подобрать документы (или их копии) - награды, дневниковые записи, фотографии и др., соответствующие теме очередной встречи.

У каждого клиента была возможность посетить от 1 до 12 индивидуальных консультаций с психологом, чтобы выстроить на основе документов и фотографий свой жизненный путь как целостный процесс и в итоге определить жанр сценария собственной жизни. Заметим, что одна половина клиентов проявляла больше самостоятельности и усердно работала дома, тогда как другая предпочитала тесное очное сотрудничество с консультантом и минимум действий в домашних условиях.

Анализ результатов повторной психодиагностики с помощью трех методик - тестов: «СЖО» Д.А. Леонтьева, «ИЖУ» Н.В. Паниной, «СПА» К. Рождерса и Р. Даймонда, в частности, расчет достоверности различий с помощью критерия Вилкоксона до и после проработки проблемы, показал: 1) рост показателей теста СЖО, что в целом говорит об увеличении степени осмысленности жизни клиентов; достоверно $(\mathrm{p} \leq 0,05)$ повысился уровень показателя «результативность жизни»; 2) позитивную динамику показателей теста ИЖУ; достоверно $(\mathrm{p}<0,05)$ повысился уровень выраженности шкал: «общий фон настроения» и «общая жизненная удовлетворенность»; 3) заметно повысился уровень показателей СПА, достоверно ( $\leq \leq 0,05)$ повысился уровень показателя «адаптация».

Таким образом, пригодность гендерочувствительной нарративно-биографической модели для работы с клиентами, переживающими кризис старости, можно считать подтвержденной.

В заключение напомним научно доказанное утверждение о том, что, теряя физические силы по мере старения, человек может сохранять способность прогрессивно развиваться как личность [1, с. 60].

К этому стоит добавить: непременным условием сохранения тенденции прогрессивного развития личности является организация психологической помощи мужчинам и женщинам в возрасте кризиса перехода к старости (понятно, что в этом случае помощь носит преимущественно профилактический характер).

Как показало наше исследование, около $30 \%$ людей в возрасте от 56 до 70 лет переживают кризис старости, а это значит, что они нуждаются в психологической помощи, способствующей разрешению комплекса проблем эмоциональных, когнитивных, поведенческих и ценностно-смысловых в каждой из четырех сфер их локализации: 1) тело (адаптация к возрастным телесным и психофизиологическим изменениям, укрепление физического и психического здоровья); 2) деятельность (жизненное планирование и целенаправленное использование оставшихся лет жизни; поддержка усилий ролевой переориентации стареющего человека в поиске новых социальных и межличностных ролей; формирование 
новых интересов и освоение новых видов социально-культурной деятельности, позволяющих заполнить досуг, расширить кругозор, адаптироваться к жизни в динамике стремительно меняющегося социобытия); 3) общение (противостояние негативным социальным стереотипам; удовлетворение потребности в самовыражении, социальном признании, общении, уважении окружающих, психологической поддержке, обмене жизненным опытом; обретение позитивного социального статуса и чувства личностной значимости; разрешение межличностных конфликтов, укрепление социальных и межличностных связей и контактов; поддержка чувства собственной полноценности; профилактика аффективного обеднения, связанного с потерей близких людей и обособлением детей, эмоциональной черствости, подкрепление стремления к аффективному обогащению в других формах; стремление к душевной гибкости (преодоление психической ригидности); поиск новых форм поведения); 4) уединение и саморазвитие (адекватное восприятие старости; разумная оценка оставшегося времени жизни, построение реально выполнимого плана жизненных занятий; стремление к внутренней целостности и осмыслению прожитой жизни; для одиноких пожилых людей - превращение вынужденного одиночества в творческое уединение).

В этом случае психологическая помощь пожилым клиентам является коррекционно-профилактической, а возрастной кризис используется как сенситивный период для развития личности.

\section{ЛИТЕРАТУРА:}

1. Анцыферова Л.И. Поздний период жизни человека: типы старения и возможности поступательного развития личности // Психологический журнал. 1996. № 6. С. 60-71.

2. Гамезо М.В., Петрова Е.А., Орлова Л.М. Возрастная и педагогическая психология. М., 2003. 512 с.

3. Геронтопсихология / Под ред. Г.С. Никифорова. СПб., 2007. 391 с.

4. Глуханюк Н.С., Гершкович Т.Б. Поздний возраст и стратегии его освоения. M., 2003. 112 c.

5. Ермолаева М.В. Психолого-педагогическое сопровождение пожилого человека. М., 2011. 464 с.

6. Ильин Е.П. Психология зрелости. СПб., 2012. 544 c.

7. Краснова О.В. Социальная психология старости / О.В. Краснова, А.Г. Лидерс. M., 2002. 288 c.

8. Кулагина И.Ю., Колюцкий В.Н. Возрастная психология: полный жизненный цикл развития человека. М., 2001. 464 c.

9. Малкина-Пых И.Г. Кризисы пожилого возраста : справочник практикующего психолога. М., 2005. 368 с.

10. Манухина Н.М. Применение нарративного подхода // Психология зрелости и старения. 2006. № 3(35). С. 74-116.

11. Реан А.А., Аверин В.А., Деркач А.А. Психология развития личности. Средний возраст, старение, смерть. СПб., 2007. 384 c.

12. Розин В.М. Психология судьбы: программирование или творчество // Вопросы психологии. 1992. №№ 1-2. C. 98-105.

13. Стюарт-Гамильтон Я. Психология старения. СПб., 2010. 320 с.

14. Сырцова А., Митина О.В. Возрастная динамика временных ориентаций личности // Вопросы психологии. 2008. № 2. C. 41-54.

15. Толстых А.В. Возрасты жизни. М., 1988. 224 c. 
16. Уайт М. Карты нарративной практики: введение в нарративную терапию. М., 2010. 326 c.

17. Хойфт Г., Крузе А., Радебольд Г. Герон- топсихосоматика и возрастная психотерапия. М., 2003. 370 с.

18. Шаповаленко И.В. Возрастная психология. М., 2009. 349 с. 